\title{
Anti-CEA immunoscintigraphy and computed tomographic scanning in the preoperative evaluation of mediastinal lymph nodes in lung
} \section{cancer} Gianfranco Buccheri, Alberto Biggi, Domenico Ferrigno, Maurizio Quaranta,
Alessandro Leone, Giuseppe Vassallo, Francesco Pugno
Advances in immunology over the last decades have led to improved methods for producing radiolabelled antibodies that target tumour antigens in vivo. ${ }^{1}$ In patients with lung cancer several studies have shown that immunoscintigraphy may detect the primary tumour and the possible presence of regional and distant metastases. ${ }^{2-18}$ In 13 of 17 clinical investigations so far available for evaluation, tumour targeting was attempted with anti-carcinoembryonic antigen (CEA) antibodies, ${ }^{2-46-101214-17}$ and anti-CEA immunoscintigraphy can be regarded as the standard for immunoscintigraphic diagnosis. In a recent review of studies of anti-CEA immunoscintigraphy in lung cancer ${ }^{19}$ the average detection rates for primary, mediastinal, and distant tumour metastases were $87 \%$ (216 of 248 patients), $70 \%$ (49 of 70 ), and $84 \%$ (109 of 130 ), respectively. In the same analysis corresponding specificities were $54 \%$ (13 negative scans of 24 benign lesions), $80 \%$ (103 of 129), and $84 \%$ (109 of 130).

Clinical studies using indium-111 labelled $\mathrm{F}\left(\mathrm{ab}^{\prime}\right) 2$ fragments of the anti-CEA monoclonal antibody FO23C5 have been carried out by our group since November $1987 .^{71012}$ We aimed to evaluate the role of planar and single photoemission computed tomography (SPECT) immunoscintigraphy images in the thoracic assessment of resectability. The present report focuses on the preoperative evaluation of mediastinal lymph nodes which, based on our earlier studies, seemed the most fruitful field of application for immunoscintigraphy.

\section{Methods}

PATIENTS AND STUDY DESIGN

Eligible patients either had histologically proved lung cancer or were so strongly suspected of having lung cancer to be offered a diagnostic and possibly curative thoracotomy. All were considered operable after a preliminary evaluation based on history, physical examination, blood chemistry and haematological counts, bronchoscopy, lung function tests, chest radiographs and other tests, as required by the results of the above evaluation. $\mathrm{Re}$ gistered patients underwent additional mandatory investigations including anti-CEA immunoscintigraphy (both planar and SPECT images), technetium-99 labelled methylene diphosphonate bone scan, and CT scans of the thorax, upper abdomen, and brain. Other
Keywords: lung cancer, preoperative thoracic staging, computed tomography, immunoscintigraphy. \begin{abstract}
87 patients, but in only 80 of them was the diagnosis of lung cancer eventually confirmed.

Results - The diagnostic accuracy of planar immunoscintigraphy, SPECT immunoscintigraphy, and CT scanning for N2 disease was $76 \%, 74 \%$, and $71 \%$, respectively. The corresponding sensitivity and specificity rates were $45 \%, 77 \%, 64 \%$ and $88 \%, 72 \%$, and $74 \%$. These were not significantly different.

Conclusions - This study shows that antiCEA immunoscintigraphy has no advantage over conventional CT scanning in assessing mediastinal lymphoadenopathy in patients with lung cancer. CT scanning remains the gold standard test in these patients.

(Thorax 1996;51:359-363)
\end{abstract}




\begin{tabular}{|c|c|c|c|}
\hline & Registered patients $(n=131)$ & Assessable patients $(n=87)$ & $\begin{array}{l}\text { Assessable patients with } \\
\text { lung cancer }(n=80)\end{array}$ \\
\hline Mean $(95 \% \mathrm{CI})$ age (years) & $62.28(60.93$ to 63.63$)$ & $61.48(59 \cdot 78$ to $63 \cdot 17)$ & $61.54(59.79$ to 63.30$)$ \\
\hline Sex (male/female) & $112 / 19$ & $73 / 14$ & $69 / 11$ \\
\hline $\begin{array}{l}\text { Karnofsky performance status } \\
(70 / 80 / 90 / 100)\end{array}$ & $38 / 30 / 42 / 21$ & $19 / 19 / 29 / 20$ & $19 / 18 / 26 / 17$ \\
\hline $\begin{array}{l}\text { Weight loss in } 6 \text { months }(\%) \\
(95 \% \mathrm{CI})\end{array}$ & $3.1(2.25$ to 3.94$)$ & $1.93(1.16$ to 2.69$)$ & $1.88(1.09$ to 2.77$)$ \\
\hline $\begin{array}{l}\text { Serum carcinoembryonic antigen } \\
(\mathrm{ng} / \mathrm{ml})(95 \% \mathrm{CI})\end{array}$ & $9.01(3.49$ to 14.53$)$ & $5.43(3.11$ to $7 \cdot 76)$ & $5.69(3.21$ to $8 \cdot 17)$ \\
\hline Histology $(\mathrm{E} / \mathrm{A} / \mathrm{S} / \mathrm{L} / \mathrm{U} / \mathrm{O} / \mathrm{B})$ & $67 / 27 / 11 / 8 / 11 / 1 / 6$ & $43 / 26 / 3 / 6 / 2 / 1 / 6$ & $43 / 26 / 3 / 6 / 2$ \\
\hline $\begin{array}{l}\text { Tumour location (central/ } \\
\text { peripheral) }\end{array}$ & $85 / 46$ & $61 / 26$ & $57 / 23$ \\
\hline \multicolumn{4}{|c|}{$\begin{array}{l}\text { Disease extent (best assessment, TNM } \\
\text { category) }\end{array}$} \\
\hline $\mathrm{T} 1-2 / \mathrm{T} 3 / \mathrm{T} 4$ & $91 / 17 / 23$ & $63 / 9 / 8$ & $63 / 9 / 8$ \\
\hline $\mathrm{N} 1 / \mathrm{N} 2 / \mathrm{N} 3$ & $57 / 13 / 49 / 5$ & $49 / 9 / 19 / 3$ & $49 / 9 / 19 / 3$ \\
\hline $\mathrm{M} 0 / \mathrm{M} 1$ & $115 / 16$ & $76 / 4^{*}$ & $76 / 4^{*}$ \\
\hline \multicolumn{4}{|l|}{$\begin{array}{l}\text { Immunoscintigraphy technical } \\
\text { notes }(95 \% \text { CI })\end{array}$} \\
\hline Dose of immunoreagent $(\mu \mathrm{g})$ & $277.82(257.79$ to 297.84$)$ & $271.95(247 \cdot 14$ to $296 \cdot 76)$ & $272 \cdot 17(245 \cdot 79$ to $298 \cdot 55)$ \\
\hline Total radioactivity $(\mathrm{mCi})$ & $4.85(4.62$ to 5.07$)$ & $4.75(4.58$ to 4.93$)$ & $4.71(4.54$ to 4.88$)$ \\
\hline Labelling efficiency (\%) & $92.65(90.22$ to 95.07$)$ & $94.42(91.96$ to 96.87$)$ & $94.18(91.54$ to 96.82$)$ \\
\hline
\end{tabular}

$\mathrm{E}=$ epidermoid carcinoma; $\mathrm{A}=$ adenocarcinoma; $\mathrm{S}=$ small cell carcinoma; $\mathrm{L}=$ large cell carcinoma; $\mathrm{U}=$ undefined cell type or mixed histology; $\mathrm{O}=$ cancer other than bronchial carcinoma, $\mathrm{B}=$ pulmonary benign disease.

* Pulmonary micromestases discovered at thoracotomy.

imaging studies such as bone radiographs and CT scans or ultrasonographic studies of the abdomen were done to support a diagnosis or to guide needle aspirations and biopsies. All staging tests were obtained within a 3-4 week period and surgery was performed within 30 days of the first hospital admission or outpatient visit. Tumour cell type and stage of disease were classified according to internationally adopted criteria. $^{2021}$

Patients were informed of the nature, aim, potential risks, and benefits of both immunoscintigraphy and iodine contrast CT scanning and gave their consent before entering the study. Anthropometric and clinical characteristics of all eligible patients including age, sex, Karnofsky performance status, weight loss, serum CEA level, histological type, endobronchial tumour location, and disease extent are summarised in table 1 .

\section{IMMUNOSCINTIGRAPHY}

Anti-CEA FO23C5 $\mathrm{F}\left(\mathrm{ab}^{\prime}\right) 2$ fragments supplied as an instant labelling kit (Indomab-k2) are licensed to Sorin Biomedica (Saluggia, Italy). The kit contains $0.3 \mathrm{mg}$ of a lyophilised preparation of monoclonal antibody fragments previously conjugated to the bifunctional chelating agent diethylenetrioninepentaacetic acid (DTPA). Details concerning the production and properties of the whole antibody and its derived fragment have been previously reported. ${ }^{40}$

Radiolabelling was obtained following the manufacturer's instructions and its quality verified by gel chromatography column scanning. ${ }^{410}$ The final solution was administered within two hours of being prepared. Characteristics of the injected radiopharmaceutical (dose of antibody fragments, total radioactivity, and radiolabelling efficiency) are shown in table 1.

Planar spot images (anterior and posterior views of the thorax and abdomen, anterior and lateral views of the head) were acquired by a large field of view gamma camera (GE 400 ACT, General Electric, Milwaukee, Wisconsin,
USA) fitted with a medium energy parallel hole collimator using a dual energy window (173-274 keV). Views were stored in a $128 \times 128$ matrix. At least one scintigraphic series, acquired 120 hours after the radio compound injection, was obtained. At each scanning time a $1500 \mathrm{~K}$ anterior view of the thorax was recorded while the other images were recorded for a preset time. After planar imaging SPECT views of the thorax were obtained. The patient was positioned supine with arms above the head and the thorax was centred underneath the camera. Sixty four planar images were collected around $360^{\circ}$ with a $64 \times 64$ word mode matrix. The acquisition time for each plane was $20-25$ seconds. The 64 planar projections were reconstructed to transverse slices with the use of a Butterworth filter (cutoff frequencies $0.3-0.4 \mathrm{cyles} / \mathrm{cm}$, power factor 20 ) at a two pixel thickness for each transverse $\left(12.8 \mathrm{~mm}\right.$ thick) slice. A value of $0.04 \mathrm{~cm}^{-1}$ was used as attenuation coefficient. Transverse sections were reorientated into the sagittal and coronal planes.

The criteria for the interpretation of immunoscintigraphic images have already been described in detail. ${ }^{1012}$ Mediastinal lesions were assigned to a definite nodal station according to topographical criteria and the ATS node mapping scheme. ${ }^{22}$ All immunoscintigraphy scans were interpreted by a specialist in nuclear medicine (A.B.) without the benefits of clinical information.

\section{THORACIC COMPUTED TOMOGRAPHY}

All thoracic CT scans were performed with a GE 9800 scanner (General Electric, Milwaukee, Wisconsin, USA). Sections $10 \mathrm{~mm}$ thick were obtained at $1 \mathrm{~cm}$ intervals during suspended inspiration from the lung apices to the upper abdomen. In selected cases $5 \mathrm{~mm}$ thick sections were obtained at $5 \mathrm{~mm}$ intervals through the region of interest. Iodinated intravenous contrast medium $(150 \mathrm{ml}$ bolus and $100 \mathrm{ml}$ in slow infusion) was injected before all studies. Appropriate windows were used for viewing both lungs and soft tissues. Mediastinal 
nodes were labelled as abnormal if they were $1 \mathrm{~cm}$ or larger (short axis) and $/$ or $1.5 \mathrm{~cm}$ or longer (long axis) on the transverse plane images. Enlarged mediastinal lymph nodes were ascribed to a definite nodal station by the American Thoracic Society (ATS) classification. ${ }^{22}$ All CT scans were blindly reviewed by an experienced radiologist (A.L.).

\section{SURGICAL SAMPLING AND PATHOLOGICAL EXAMINATION}

At surgery all nodal stations that were positive on either CT or SPECT images were carefully inspected and sampled, even when lymph nodes appeared macroscopically normal. All enlarged, palpable, or visible nodes were totally removed. In apparently normal mediastinums with negative preoperative studies a minimum sampling of three node stations was required to reject the hypothesis of N2 disease. Mediastinoscopies (and, in one case, left anterior mediastinotomy) were performed when CT or immunoscintigraphy studies were positive for accessible lymph nodes in otherwise operable patients. Removed lymph nodes were fixed separately in $10 \%$ neutral buffered formalin and labelled according to the ATS criteria. ${ }^{22}$

\section{STATISTICAL ANALYSIS}

Immunoscintigraphy can be done using either a planar imaging technique, a SPECT technique, or both. In this study both techniques were used which gave us the opportunity to obtain (and compare) two different results for one immunoscintigraphic series. With reference to the pathological data, the results of planar immunoscintigraphy, SPECT immunoscintigraphy, and CT scanning were designated true positive, false positive, true negative, and false negative for $\mathrm{N} 2$ metastases. Values for sensitivity, specificity, accuracy, and predictive capabilties were calculated according to the formula of Galen. ${ }^{23}$ Proportions were furnished with their $95 \%$ confidence interval. ${ }^{24}$ Differences in proportions observed in the same patients were tested statistically using the MacNemar test. ${ }^{25}$ The $\chi^{2}$ test was used for other comparisons between proportions. ${ }^{25}$ The statistical significance level was set at $5 \%$, all tests being two tailed.

\section{Results}

CHARACTERISTICS OF PATIENTS

Between November 1987 and October 1994 131 eligible patients ( 112 men) were registered (table 1). The final diagnosis was squamous cell carcinoma in 67 patients, small cell lung cancer in 11 , adenocarcinoma in 27 , large cell anaplastic carcinoma in eight, undefined cell type or mixed histology lung cancer in 11, Hodgkin's disease in one, and non-malignant lung lesions in six including one hamartochondroma, one fibrocaseous tuberculosis, two sclerosing bronchiectasis, and two persistent foci of pneumonitis with features of interstitial alveolitis and fibrosis. All patients had a Karnofsky score ${ }^{26}$ of 70-100 and no other contra- indication to radical surgery. At the end of presurgical staging 27 patients were judged inoperable based on unequivocal CT findings, nine withdrew their consent to a probably noncurative thoracotomy, and eight were found to have small cell lung cancer after enrollment and were given chemotherapy. Of the remaining 87 patients 70 underwent a resection, seven underwent mediastinoscopy or mediastinotomy alone, and 10 had both cervical or (parasternal) exploration and a thoracotomy. Seven had benign lesions and, histologically, the most frequent tumour cell type was squamous (43 of the 80 assessable patients with cancer). Fifty seven of these 80 lung tumours were in the distal bronchi. Table 1 summarises the clinical, scintigraphic, and pathological characteristics of the three groups of patients (131 registered, 87 assessable, and 80 with cancer).

\section{DETECTION OF MEDIASTINAL LYMPH NODE INVOLVEMENT}

Table 2 shows the main findings of the study. True positive, true negative, false positive, and false negative results, along with the corresponding values (and 95\% confidence interval) for sensitivity, specificity, and accuracy, are listed. Data refer to the two groups of patients - that is, all the assessable and those assessable with cancer - and to the three types of investigation - that is, planar immunoscintigraphy, SPECT immunoscintigraphy, and CT scanning. In patients with cancer, tumour lymph node extension to the mediastinum was equally detectable by all three techniques. Diagnostic accuracy was $76 \%, 74 \%$, and $71 \%$ for planar immunoscintigraphy, SPECT immunoscintigraphy, and CT scanning, respectively; sensitivity ranged from $77 \%$ with SPECT immunoscintigraphy to $45 \%$ with planar immunoscintigraphy and specificity from $88 \%$ with planar immunoscintigraphy to $72 \%$ with SPECT immunoscintigraphy. There were no statistically significant differences with the MacNemar test. Planar immunoscintigraphy and SPECT immunoscintigraphy was the best matched combination since the first technique was the most specific and the latter the most sensitive. CT images retained intermediate status. All staging techniques shared a high negative predictive capability, with SPECT immunoscintigraphy approximating $90 \%$. Overall, similar figures were obtained when the seven patients without lung cancer were included in the computation (table 2). However, most findings in this subgroup of seven patients were falsely positive, particularly with SPECT immunoscintigraphy.

\section{Discussion}

Surgery remains the only prospect of cure in patients with non-small cell lung cancer. ${ }^{27}$ Ideally, the preoperative assessment of the mediastinum should save patients from futile surgery. On the other hand, patients should be offered a surgical cure if appropriate. The final evaluation of the mediastinum often depends on surgical staging procedures such as media- 
Table 2 Diagnostic formulae: N2 disease by technique of evaluation

\begin{tabular}{|c|c|c|c|c|c|c|c|c|c|c|}
\hline & $T P$ & $T N$ & $F P$ & $F N$ & Total & Sensitivity & Specificity & Accuracy & $P P V$ & $N P V$ \\
\hline \multicolumn{11}{|l|}{ Assessable patients } \\
\hline $\begin{array}{l}\text { Planar } \\
\text { immunoscintigraphy }\end{array}$ & 10 & 57 & 8 & 12 & 87 & $45 \%$ ( $25 \%$ to $66 \%)$ & $88 \%(80 \%$ to $96 \%)$ & $77 \%(68 \%$ to $86 \%)$ & $56 \%(33 \%$ to $79 \%)$ & $83 \%(74 \%$ to $92 \%)$ \\
\hline $\begin{array}{l}\text { SPECT } \\
\text { immunoscintigraphy }\end{array}$ & 17 & 46 & 19 & 5 & 87 & $77 \%(60 \%$ to $95 \%)$ & $71 \%(60 \%$ to $82 \%)$ & $72 \%(63 \%$ to $82 \%)$ & $47 \%(31 \%$ to $64 \%)$ & $90 \%(82 \%$ to $98 \%)$ \\
\hline $\begin{array}{l}\text { Thoracic CT } \\
\text { scanning }\end{array}$ & 14 & 49 & 16 & 8 & 87 & $64 \%(44 \%$ to $84 \%)$ & $75 \%(65 \%$ to $86 \%)$ & $72 \%(63 \%$ to $82 \%)$ & $47 \%(29 \%$ to $65 \%)$ & $86 \%(77 \%$ to $95 \%)$ \\
\hline \multicolumn{11}{|c|}{ Assessable patients with lung cancer } \\
\hline $\begin{array}{l}\text { Planar } \\
\text { immunoscintigraphy }\end{array}$ & 10 & 51 & 7 & 12 & 80 & $45 \%$ ( $25 \%$ to $66 \%)$ & $88 \%(80 \%$ to $96 \%)$ & $76 \%(67 \%$ to $86 \%)$ & $59 \%(35 \%$ to $82 \%)$ & $81 \%(71 \%$ to $91 \%)$ \\
\hline $\begin{array}{l}\text { SPECT } \\
\text { immunoscintigraphy }\end{array}$ & 17 & 42 & 16 & 5 & 80 & $77 \%(60 \%$ to $95 \%)$ & $72 \%(61 \%$ to $84 \%)$ & $74 \%(64 \%$ to $83 \%)$ & $52 \%(34 \%$ to $69 \%)$ & $89 \%(81 \%$ to $98 \%)$ \\
\hline $\begin{array}{l}\text { Thoracic CT } \\
\text { scanning }\end{array}$ & 14 & 43 & 15 & 8 & 80 & $64 \%(44 \%$ to $84 \%)$ & $74 \%(63 \%$ to $85 \%)$ & $71 \%(61 \%$ to $81 \%)$ & $48 \%(30 \%$ to $66 \%)$ & $84 \%(74 \%$ to $94 \%)$ \\
\hline
\end{tabular}

$\mathrm{TP}=$ true positive; $\mathrm{TN}=$ true negative; $\mathrm{FP}=$ false positive; $\mathrm{FN}=$ false negative $\mathrm{PPV}=$ positive predictive value $\mathrm{NPV}=$ negative predictive value; $\mathrm{SPECT}=$ single photoemission computed tomography; $\mathrm{CT}=$ computed tomography.

Values are percentages with $95 \%$ confidence intervals.

stinoscopy and anterior mediastinotomy. ${ }^{27-31}$ Cervical mediastinoscopy detects gross, usually widespread, disease of the nodes in the superior mediastinum ${ }^{28-30}$ and, when positive, prevents a useless operation. ${ }^{27}$ In the same way, anterior mediastinotomy has a particular role in suspected para-aortic and subaortic lymphoadenopathy. ${ }^{31}$ These intermediate surgical techniques require skill and carry potentially serious complications ${ }^{30}$ and additional hospital costs.

Thus, a reliable non-invasive test might be useful in limiting mediastinoscopy by selecting subgroups of patients with various probabilities of mediastinal involvement. Using such a test as a filter, patients with a low likelihood of mediastinal lymphoadenopathy could go straight to thoracotomy while others would receive a prior mediastinoscopy. ${ }^{27}$ Besides an acceptable rate of overall accuracy, this strategy requires the "filter-test" to have low rates of false negative results, possibly less than $10 \%$, to reduce the incidence of unexpected $\mathrm{N} 2$ disease found at thoracotomy. CT scanning is usually used for this purpose. ${ }^{28} \mathrm{~A}$ meta-analysis of 42 early studies on CT scanning published in 1990 documented an average accuracy of $80 \% .^{32}$ However, more recent estimates have suggested more prudent figures of $50-60 \%$ in the USA and $60-70 \%$ in Europe and Japan. ${ }^{33} 34$ These figures suggest that thoracic CT scanning may not therefore have the accuracy needed for an ideal filter test.

Several studies have evaluated anti-CEA immunoscintigraphy in the diagnosis of lung cancer. $^{2-46-101214-17}$ Less information is available, however, concerning the staging potential of this technique. ${ }^{8101214-17}$ Excluding the data shown in the current report, all available information is restricted to about 100 patients and is limited by the inhomogeneity of studies. $^{814-17}$ For example, different commercially available immunoreagents (including the $F\left(a b^{\prime}\right) 2$ fragments of the $F 6$ antibody, ${ }^{15}$ the $F\left(a b^{\prime}\right) 2$ fragments of BW431/31, ${ }^{14}$ and the intact BW431/26 $6^{814}$ ) have been used and labelled to different radionuclides (indium$111,{ }^{1416}$ technetium-99, ${ }^{814}$ and iodine- $131^{17}$ ). Furthermore, the clinical target has varied in the different studies up to the extreme in the study of MacMillan et al ${ }^{15}$ who only considered patients with small cell lung cancer, and no separate analysis has been made for lymphatic spread and direct invasion of mediastinum..$^{81415}$ Above all, SPECT images were not always obtained. ${ }^{81415}$ This has caused inconsistent results with sensitivities in the range $40-75 \%$ and specificities in the range of $33-81 \% .^{814-17} \mathrm{Be}$ cause of these inconsistencies we believe that the results of our study on the value of antiCEA immunoscintigraphy in the preoperative mediastinal assessment are important.

In a previous report of 63 patients with lung cancer, ${ }^{10}$ where we investigated the diagnostic yield of total body scintigraphy with ${ }^{111}$ In labelled $F\left(a b^{\prime}\right) 2$ fragments of the anti-CEA monoclonal antibody $\mathrm{FO} 23 \mathrm{C} 5$, the diagnosis of mediastinal lymph node metastases was correct in about $85 \%$ of patients using both the clinical and the pathological reference criteria. We then decided to perform a formal comparison between diagnostic yields of CT scanning and anti-CEA immunoscintigraphy. A preliminary report of this comparison was published two years ago. ${ }^{12}$ In the present study we report more mature data that are not substantially different. Current accuracy rates for $\mathrm{N} 2$ disease in pathologically documented cases are, respectively, $76 \%$ for planar immunoscintigraphy, $74 \%$ for SPECT immunoscintigraphy, and $71 \%$ for CT scanning. However, the gain in accuracy appears negligible, and the accuracy of the three techniques and the predictive values of a negative test $(81 \%, 89 \%$, and $84 \%$, respectively, for planar immunoscintigraphy, SPECT immunoscintigraphy, and CT scanning) are not significantly different and all are within the lowest boundary of an acceptable "filter test". It must be remembered also that the search for nodal metastases was the most promising application of anti-CEA immunoscintigraphy in lung cancer staging ${ }^{12}$ and that immunoscintigraphy is a time consuming and very expensive technique. For all these reasons, we now feel that there is no justification to prefer anti-CEA immunoscintigraphy to standard CT scanning of the thorax.

In conclusion, we believe that in lung cancer the ideal non-invasive preoperative test is not yet available and thoracic CT scanning remains the standard test for large and/or central tumours.

The authors wish to acknowledge the skill and dedication of Mrs Monica Viale, nurse of the outpatients unit of their hospital. 
They are also indebted to the Cuneo Lung Cancer Study Group (Cu.L.Ca.S.G.) for the financial support.

1 Epenetos AA, Kosmas C. Monoclonal antibodies for imaging and therapy. Br f Cancer 1989;59:152-5.

2 Riva P, Paganelli G, Callegaro L, Bartoli MG, Turci D, Benini S, et al. Immunoscintigraphy of adenocarcinomas by means of 111 In-labelled $\mathrm{F}\left(\mathrm{ab}^{\prime}\right) 2$ fragments of antiby means of 111 In-labelled $\mathrm{F}\left(\mathrm{ab}^{\prime}\right) 2$ fragments of antiCEA monoclonal

3 Riva P, Moscatelli G, Paganelli G, Benini S, Siccardi A. Antibody-guided diagnosis: an Italian experience on CEA expressing tumours. Int $\mathcal{F}$ Cancer 1988;42(Suppl 2):11420 .

4 Siccardi AG. Studio multicentrico sulla immunoscintigrafia degli adenocarcinomi CEA secernenti. Valutazione dell'efficacia diagnositca di frammenti $F\left(a b^{\prime}\right) 2$ radiomarcati dell'anticorpo monoclonale FO23C5 anti-CEA condotto in 11 Centri di Medicina Nucleare su 509 pazienti portatori di adenocarcinomi. Consiglio Nazionale delle Richerche, Progetto Finalizzato Tecnologie Biomediche e Sanitarie, Sottoprogetto 11. Roma: Consiglio Nazionale delle Ricerche (CNR), 1989; Roma:

5 Bourget P, Dazord L, Desrues B, Collet B, Ramee MP, Delaval $\mathrm{P}$, et al. Immunoscintigraphy of human lung squamous cell carcinoma using an iodine-131 labelled monoclonal antibodies (Po66). Br f Cancer 1990;61:2304.

6 Krishnamurthy S, Morris JF, Antonovic R, Ahmed A, Galey WT, Duncan C, et al. Evaluation of primary lung cancer with Indium-111 anti-carcinoembryonic antigen (type ZCE-025) monoclonal antibody scintigraphy. Cancer 1990;65:458-65.

7 Biggi A, Buccheri GF, Ferrigno D, Viglietti A, Farinelli MC, Comino A, et al. Detection of suspected primary lung cancer by scintigraphy with indium-111 anti-carcinoembryonic antigen monoclonal antibodies (type FO23C5). 7 Nucl Med 1991;32:2064-8.

8 Leitha T, Walter R, Schlick W, Dudczak R. $99 \mathrm{mTc}$ TantiCEA radioimmunoscintigraphy of lung adenocarcinoma. Chest 1991;99:14-9.

9 Torres M, Jimenez-Heffernan A, Valverde A, Gonzel FM, Latre JM, Llamas JM, et al. Immunoscintigraphy of lung
cancer using ${ }^{111}$ In-labelled antiCEA FO23C5-F(ab')2. Nuclear Med Commun 1991;12:937--50.

10 Buccheri GF, Biggi A, Ferrigno D, D'Angeli B, Vassallo G, Leone $\mathrm{A}$, et al. Imaging lung cancer by scintigraphy with Indium-111 labeled $\mathrm{F}\left(\mathrm{ab}^{\prime}\right) 2$ fragments of the anticarcinoembryonic antigen monoclonal antibody $\mathrm{FO} 23 \mathrm{C} 5$. Cancer 1992;70:749-59.

11 Perkins AC, Pimm MV, Morgan DAL, Wastie ML, Reynolds JR, Baldwin RW. ${ }^{131}$ I and ${ }^{111}$ In-labelled monoclonal antibody imaging of primary lung carcinoma. Nucl Med Combody imaging of prim

12. Buccheri G, Biggi A, Ferrigno D, Leone A, Taviani $M$, Quaranta M. Anti-CEA immunoscintigraphy might be more useful than computed tomography in the preoperative thoracic evaluation of lung cancer. Chest 1993; 104:734-42.

13 Colombo P, Paganelli G, Magnani P, Songini C, Facio F, Faglia G. Immunoscintigraphy with anti-chromogranin $\mathrm{A}$ antibodies with endocrine/neuroendocrine tumors. $\mathcal{f}$ Endocrinol Invest 1993;16:841-3.

14 Kairemo KJA, Aronen HJ, Liewendahl K, Paavonen T, Heikkonen JJ, Virkkunen P, et al. Radioimmunoimaging of non-small cell lung cancer with ${ }^{111} \mathrm{In}$ - and ${ }^{99 \mathrm{~m}} \mathrm{Tc}$-labeled monoclonal anti-CEA-antibodies. Acta Oncol 1993;32 771-8.

15 Macmillan CH, Perkins AC, Wastie ML, Leach IH, Morgan DAL. Immunoscintigraphy of small-cell lung cancer: A study using technetium and indium labelled anti-carcinoembryonic antigen monoclonal antibody preparations. Br f Cancer 1993;67:1391-4.

16 Vuillez J-P, Moro D, Brambilla E, Brichon P-Y, Ferretti $\mathrm{G}$, Saccavini JC, et al. Immunoscintigraphy using "'Inlabelled $F\left(a b^{\prime}\right) 2$ fragments of anti-carcinoembryonic antigen (CEA) monoclonal antibody for staging of non-small gen (CEA) monoclonal antibody for staging of non-small

17 Boilleau G, Pujol JL, Ychou M, Faurous P, Marty-Anẹ C, Michel FB, et al. Detection of lymph node metastases in lung cancer: comparison of ${ }^{131}$ In-anti-CEA-antiCA19-9 immunoscintigraphy versus computed tomography. Lung Cancer 1994;11:209-19.

18 O'Byrne KJ, Ennis JT, Freyne PJ, Clancy LJ, Prichard JS, Carney DN. Scintigraphic imaging of small-cell lung cancer with [" In] Inentetreotide, a radiolabelled somatostatin analogue. $B r \mathcal{F}$ Cancer 1994;69:762-6.

19 Buccheri G, Biggi A, Ferrigno D. Anti-CEA monoclonal antibody scintigraphies in lung cancer. Lung Cancer 1994; antibody scintigraphies in lung

20 World Health Organization. International histological classification of tumours. Berlin: Springer-Verlag, 1991.

21 UICC. TNM Classification of malignant tumours. Berlin: Springer-Verlag, 1987:69-73.

22 American Joint Committee on Cancer. Purposes and principles of staging. In: Beahrs OH, Earl Henson D, Hutter RVP, Myers MH, eds. Manual for staging of cancer. Philadelphia: Lippincott, 1988:3-10.

23 Galen RS. Predictive values of laboratory tests. Am 7 Cardiol 1975;36:536-8.

24 Bulpitt CJ. Confidence intervals. Lancet 1987;i:494-7.

25 Siegel S. Nonparametric statistics for the behavioural sciences. New York: MacGraw Hill, 1956.

26 Karnofsky DA, Burchenal JH. The clinical evaluation of chemotherapeutic agents in cancer. In: Macleod CM, ed. Evaluation of chemotherapeutic agents. New York: Columbia University Press, 1949:199-205.

27 Goldstraw P. The practice of cardiothoracic surgeons in the perioperative staging of non-small cell lung cancer. Thorax 1992;47:1-2.

28 Unruh $\mathrm{H}$, Chu-Jeng Chu CR. Mediastinal assessment for staging and treatment of carcinoma of the lung. Ann Thorac Surg 1986;41:224-9.

29 Ginsberg RJ. Evaluation of the mediastinum by invasive techniques. Surg Clin North Am 1987;67:1025-35.

30 Foster ED, Munro DD, Dobell ARC. Mediastinoscopy: a review of anatomical relationships and complications a review of anatomical relationships and complication

31 Bowen TE, Zajtchuk R, Green DC, Brott WH. Value of anterior mediastinotomy in bronchogenic carcinoma of the left upper lobe. $\mathcal{F}$ Thorac Cardiovasc Surg 1978;76: 269-71.

32 Dales RE, Strak RM, Raman S. Computed tomography to stage lung cancer. Approaching a controversy using metaanalysis. Am Rev Respir Dis 1990;141:1096-101.

33 Armstrong P. Preoperative computed tomographic scanning for staging lung cancer. Thorax 1994;49:941-3.

34 Mori K, Yokoi K, Saito Y, Tominaga K, Miyazawa N. Diagnosis of mediastinal lymph node metastases in lung cancer. Fpn f Clin Oncol 1992;22:35-40. 